\title{
Homogeneous Liquid-Liquid Extraction (HoLLE) of Palladium in Real Plating Wastewater for Recovery
}

\author{
Takeshi Kato $^{1 *}$, Shukuro Igarashi' ${ }^{2}$, Osamu Ohno ${ }^{2}$, Shotaro Saito ${ }^{2}$, Ryo Ando ${ }^{1}$ \\ ${ }^{1}$ Industrial Technology Institute of Ibaraki Prefecture, Ibaraki, Japan \\ ${ }^{2}$ Department of Biomolecular Functional Engineering, Faculty of Engineering, Ibaraki University, Ibaraki, Japan \\ Email: "katou@kougise.pref.ibaraki.jp
}

Received 8 January 2016; accepted 23 February 2016; published 26 February 2016

Copyright (C) 2016 by authors and Scientific Research Publishing Inc.

This work is licensed under the Creative Commons Attribution International License (CC BY). http://creativecommons.org/licenses/by/4.0/

(c) (i) Open Access

\section{Abstract}

On the basis of homogeneous liquid-liquid extraction (HoLLE) with Zonyl FSA to plating water containing $1 \mathrm{mg}$ palladium, $96.6 \%$ of the palladium was extracted into the sedimented liquid phase. After phase separation, the volume ratio (Va/Vs) of the aqueous phase (Va) and the sedimented liquid phase (Vs) was $556(50 \mathrm{~mL} \rightarrow 0.09 \mathrm{~mL})$. The assessment of the potential implementation of this procedure to wastewater treatment showed that HoLLE was satisfactorily achieved when the volume was scaled up to $1000 \mathrm{~mL}$. Moreover, HoLLE was conducted to real palladium plating wastewater generated in the plating industry. $94.5 \%$ of the palladium was extracted into the sedimented liquid phase. After phase separation, the volume ratio (Va/Vs) of the aqueous phase (Va) and the sedimented liquid phase (Vs) was 500 (50 $\mathrm{mL} \rightarrow 0.1 \mathrm{~mL}$ ). In addition, HoLLE could separate palladium from coexisting metals in real plating wastewater. This knowledge is expected to lead to the development of new separation and concentration technologies of rare metals from real plating wastewater.

\section{Keywords}

Homogeneous Liquid-Liquid Extraction, HoLLE, Zonyl FSA, Surfactant, Real Plating Wastewater

\section{Introduction}

The multi-functionalization and miniaturization of electronic devices is accompanied by a growing density of their components. Highly efficient electronic devices contain many parts, such as connectors and sensors, in-

\footnotetext{
${ }^{*}$ Corresponding author.
}

How to cite this paper: Kato, T., Igarashi, S., Ohno, O., Saito, S. and Ando, R. (2016) Homogeneous Liquid-Liquid Extraction (HoLLE) of Palladium in Real Plating Wastewater for Recovery. Journal of Environmental Protection, 7, 277-286. 
volving precious metal plating. Gold plating is widely implemented in wiring and contact materials in the electronic industry because it provides excellent corrosion resistance and electric conductivity [1] [2]. However, the need for cost reducing approaches has prompted researchers to seek substitutes for gold plating. Specifically, plating processes using palladium and its alloys have been applied to electronic materials since the 1960s [3] [4]. Palladium plating provides superior chemical and mechanical properties that fulfill the characteristic requirements for the surface treated electronic components [5]-[7].

Recently, the potential use of plating wastewater as a metal resource has attracted considerable attention. Currently, most plating wastewater treatment procedures rely on sludge reclamation after pH adjustment. In Japan, plating industries have been reported to produce 50,000 tons of sludge per year, and almost all of this sludge is reclaimed [8]. Plating wastewater treatment is commonly conducted in solutions containing various metals. Contamination by other metals makes selective metal recovery difficult. It was expected that the spent plating water with the targeting metal could be isolated to avoid contamination by other metals. The metal recovery from plating wastewater has been examined by several methods such as cementation [9], precipitation [10], electrowinning [11]-[13], solid phase extraction [14] [15], and solvent extraction [16]-[18]. In addition, the metal recovery from palladium plating water has been performed by electrochemical method [19], and ion exchange resin [20].

Precious metal recovery from plating wastewater relies on economically and environmentally suitable hydrometallurgical technologies such as solvent extraction, which has been extensively applied at the industrial scale [21]-[23]. In the general solvent extraction, an interface exists between the aqueous phase and the waterimmiscible organic solvent phase. Thus, mechanical shaking is required, which increases the surface area of the contact interface and causes the solute to move through the interface. On the other hand, homogeneous liquidliquid extraction (HoLLE) has proven an effective metal recovery technology. In this method, the target solute (metal) is concentrated into small liquid phase on the basis of its phase separation from homogeneous water [24]. No interface is observed between the aqueous and organic solvent phases because the solution is homogeneous under initial conditions. In other words, the surface area of the interface is infinitely large. Therefore, HoLLE does not require vigorous mechanical shaking. Furthermore, HoLLE can achieve 100 - 100,000 fold concentration down to very low sample volumes in a few minutes [25]. In addition to various metal separation and concentration [26] [27], rare metal concentration from used home appliances has been achieved by HoLLE [28].

To lower the wastewater treatment costs, the volume of the plating wastewater is often reduced by heat treatment in a specialized facility. Therefore, an effective metal extraction system is required. To meet this requirement, in this study, an extraction system exploiting the high efficiency and recovery of HoLLE was developed for palladium plating wastewater.

\section{Materials and Methods}

\subsection{Reagents and Materials}

Palladium plating consisting of dichlorotetraammine palladium (1 wt\%), ammonium nitrate (15 wt\%), and water (84 wt\%) received from Ibaraki Plating Kogyo Co., Ltd. (Ibaraki, Japan) was used in this study. The palladium concentration of the plating water in this experiment was determined to be $4.34 \mathrm{~g} \cdot \mathrm{L}^{-1}$ by inductively coupled plasma optical emission spectrometry (ICP-OES). Aqueous metal ion solutions were prepared by diluting 1000 $\mathrm{mg} \cdot \mathrm{L}^{-1}$ standard solutions obtained from Wako Pure Chemical Industries, Ltd. (Osaka, Japan). A Zonyl FSA $\left(\mathrm{CF}_{3}\left(\mathrm{CF}_{2}\right)_{\mathrm{n}} \mathrm{CH}_{2} \mathrm{CH}_{2} \mathrm{SCH}_{2} \mathrm{CH}_{2} \mathrm{CO}_{2} \mathrm{H}, \mathrm{n}=6-8\right.$, DuPont, Tokyo, Japan) solution was prepared by diluting the pure substance with an equivalent amount of distilled water. Nitric acid, hydrochloric acid, ammonia, and other basic chemicals were obtained from Wako Pure Chemical Industries, Ltd. (Osaka, Japan). All the reagents used in this study were of analytical grade.

\subsection{Apparatus}

The following instruments were utilized in this study: an M-12 pH meter manufactured by Horiba (Kyoto, Japan), a 7780 centrifugal separator manufactured by Kubota (Tokyo, Japan), an XGT-5000WR X-ray fluorescence spectrometer manufactured by Horiba (Kyoto, Japan), and an ICP ULTIMA2 ICP-OES manufactured by Horiba (Kyoto, Japan). 


\subsection{Methods}

\subsubsection{HoLLE of a Pure Palladium Solution}

A $1000 \mathrm{mg} \cdot \mathrm{L}^{-1}$ palladium standard solution was added to a $50 \mathrm{~mL}$ centrifuge tube such that $1 \mathrm{mg}$ of palladium was placed in the tube. $13.4 \mathrm{M}$ ammonia $(1 \mathrm{~mL}$ ) was then added to the centrifuge tube, and the volume was adjusted to $30 \mathrm{~mL}$ with distilled water. The $\mathrm{pH}$ of the solution was adjusted to 2.0 using $5 \mathrm{M}$ nitric acid. Next, acetone $(10 \mathrm{~mL})$ and $50 \mathrm{v} / \mathrm{v} \%$ Zonyl FSA $(1 \mathrm{~mL})$ were added to the mixture, and the volume was adjusted to 50 $\mathrm{mL}$ with distilled water. The solution was centrifuged at $2500 \mathrm{rpm}$ for $30 \mathrm{~min}$. After phase separation, the sedimented liquid phase was collected using a microsyringe.

\subsubsection{HoLLE of Palladium Plating Water}

Palladium plating water $(30 \mathrm{~mL})$ containing $1 \mathrm{mg}$ palladium was added to a $50 \mathrm{~mL}$ centrifuge tube, and the $\mathrm{pH}$ of the solution was adjusted to 2.0 using $5 \mathrm{M}$ nitric acid. Next, acetone $(11 \mathrm{~mL})$ and $50 \mathrm{v} / \mathrm{v} \%$ Zonyl FSA (1 mL) were added to the mixture, and the volume was adjusted to $50 \mathrm{~mL}$ with distilled water. The solution was centrifuged at $2500 \mathrm{rpm}$ for $30 \mathrm{~min}$. After phase separation, the sedimented liquid phase was collected using a microsyringe.

\section{Results and Discussion}

\subsection{HoLLE of a Pure Palladium Solution}

The performance of HoLLE was evaluated for a palladium-ammine complex in weakly acidic aqueous media using Zonyl FSA. Upon the addition of $13.4 \mathrm{M}$ ammonia, the orange-colored palladium standard solution instantly became colorless and transparent, suggesting the formation of the palladium-ammine complex. On the basis of palladium-ammine complex, phase separation was satisfactorily completed by HoLLE in weakly acidic aqueous media. After phase separation, approximately $100 \mu \mathrm{L}$ of each aqueous and sedimented liquid phase were collected using a microsyringe. These solutions were then dropped onto a filter paper and analyzed by $\mathrm{X}$-ray fluorescence. The results of the analyses are shown in Figure 1. A peak for palladium was not detected in the X-ray fluorescence spectrum of the aqueous phase, but was observed in the spectrum of the sedimented liquid phase. The volume ratio can be calculated as follows:

Volume ratio $=(\mathrm{mL}$ of the aqueous phase $) /(\mathrm{mL}$ of the sedimented liquid phase $)=50 / 0.1=500$

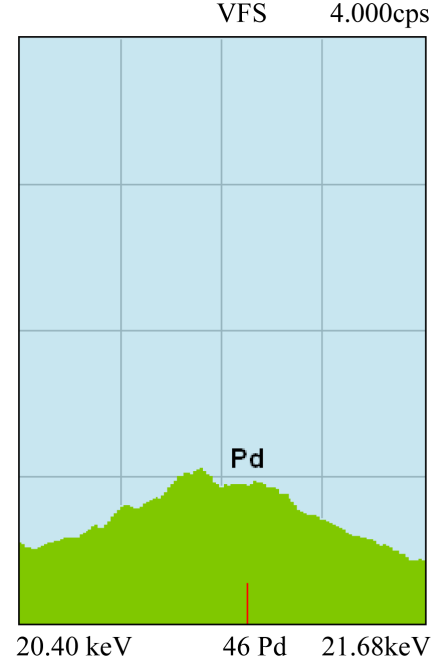

(a)

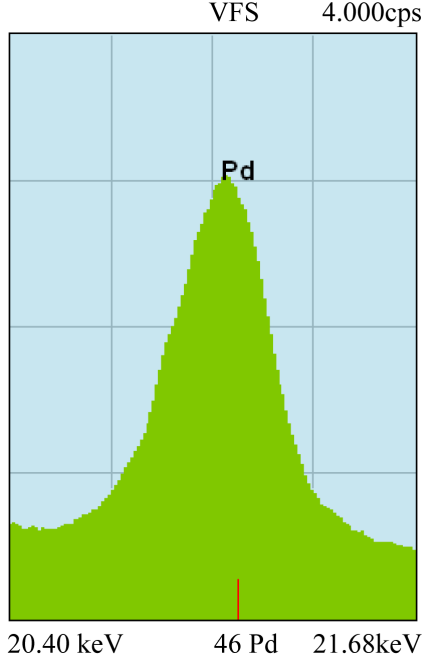

(b)

Figure 1. XRF evaluation after the HoLLE of palladium from $\mathrm{HNO}_{3}$ solution. (a) Aqueous phase, (b) Sedimented liquid phase. Added palladium weight: $1 \mathrm{mg},[\text { Ammonia }]_{\mathrm{T}}=0.267 \mathrm{M}, \mathrm{pH} 2.00$, [Acetone $]_{\mathrm{T}}=20 \mathrm{vol} . \%$, [Zonyl $\mathrm{FSA}]_{\mathrm{T}}=1.00$ vol. $\%$, (XRF measurement conditions: X-ray diameter: 1.2 $\mathrm{mm}$, time: $300 \mathrm{~s}$, voltage: $50 \mathrm{kV}$ ). 
The ICP-OES analysis of the aqueous phase revealed that $100 \%$ of the palladium was quantitatively extracted into the sedimented liquid phase, indicating that it was possible to concentrate palladium via HoLLE using Zonyl FSA.

\subsection{Optimization of HoLLE Conditions for a Pure Palladium Solution}

HoLLE using Zonyl FSA was reversible with the $\mathrm{pH}$ change in the solution, corresponding to below and above the pKa of Zonyl FSA [28]. This phase separation was achieved in the presence of hydrochloric acid, sulfuric acid, or nitric acid. The volume of the sedimented liquid phase was approximately $100 \mu \mathrm{L}$ upon the addition of acids. The palladium recovery amounted to $98.3 \%$ in hydrochloric acid, and was lower than that in sulfuric acid and nitric acid. After phase separation, the $\mathrm{pH}$ of the aqueous phase was 1.52 and 2.09 in sulfuric and nitric acid, respectively. Considering the treatment of the aqueous phase, nitric acid was chosen for the remainder of the experiment because palladium recoveries were equivalent in sulfuric and nitric acids. Moreover, optimum condition of $\mathrm{pH}$ in nitric acid was confirmed (Table 1). When phase separation was satisfactorily completed, the $\mathrm{pH}$ before and after the phase separation was acidic. Recoveries for all the above mentioned conditions in nitric acid were $100 \%$ by phase separation. Moreover, the $\mathrm{pH}$ correlated with the acid dissociation constant (pKa = 6.5 [29]) during HoLLE. On the basis of these results, it was confirmed that phase separation was completed and recovery was $100 \%$ under $\mathrm{pH} 2.0$ before phase separation. The $\mathrm{pH}$ before phase separation was set at 2.0 for the remainder of the experiment.

Next, the effect of the water-soluble organic solvent on palladium recovery was evaluated because this organic solvent significantly contributes to phase separation. When dioxane, tetrahydrofuran, or acetone was added, the phase separation was satisfactory. This suggested that the formation of the sedimented liquid phase depended on the solubility of Zonyl FSA in the water-soluble organic solvent. The volume of the sedimented liquid phase amounted to approximately $100 \mu \mathrm{L}$ in dioxane and acetone but was a little larger in tetrahydrofuran (approximately $130 \mu \mathrm{L}$ ). The palladium recovery was $94 \%$ in dioxane, which was lower than that in tetrahydrofuran and acetone. Consequently, acetone was chosen for the remainder of the experiment. The acetone concentration was then optimized when it was 0 - 30 vol.\%. Insoluble matter, which was believed to be Zonyl FSA, was detected near the sedimented liquid phase when the acetone concentration was 0 - 2 vol.\%. This insoluble matter persisted even when the sedimented liquid phase formed from $6-12$ vol.\% acetone. Because the sedimented liquid phase was satisfactorily formed in 16 - 30 vol.\% acetone, the palladium recovery was evaluated in this concentration range. Approximately $95 \%$ of the palladium was extracted in the sedimented liquid phase for these acetone concentrations (Figure 2). Therefore, the acetone concentration was set at 22 vol.\% for the remainder of the experiment.

Finally, the influence of Zonyl FSA concentration on HoLLE was determined (Figure 3). The phase separation was satisfactory when the Zonyl FSA concentration was 0.3 - 1.5 vol.\%. In addition, the volume of the sedimented liquid phase was proportional to the Zonyl FSA concentration. The palladium recovery increased with

Table 1. Influence of $\mathrm{pH}$ on the HoLLE of palladium from $\mathrm{HNO}_{3}$ solution.

\begin{tabular}{cccc}
\hline Phase separation & Recovery (\%) & $\mathrm{pH}$ (Before separation) & $\mathrm{pH}$ (After separation) \\
\hline$\times$ & - & 9.82 & 9.77 \\
$\times$ & - & 8.99 & 2.89 \\
\hline & 100 & 1.99 & 2.30 \\
\hline & 100 & 1.85 & 2.01 \\
$\circ$ & 100 & 1.66 & 1.63 \\
\hline & 100 & 1.40 & 1.42 \\
\hline
\end{tabular}

The pH (Before separation) was measured before addition of Zonyl FSA and acetone. Added palladium weight: 1 mg, [Ammonia $]_{\mathrm{T}}=0.267 \mathrm{M}$, [Acetone $]_{\mathrm{T}}=20$ vol. $\%$, [Zonyl FSA $]_{\mathrm{T}}=1.00$ vol. $\%$. 


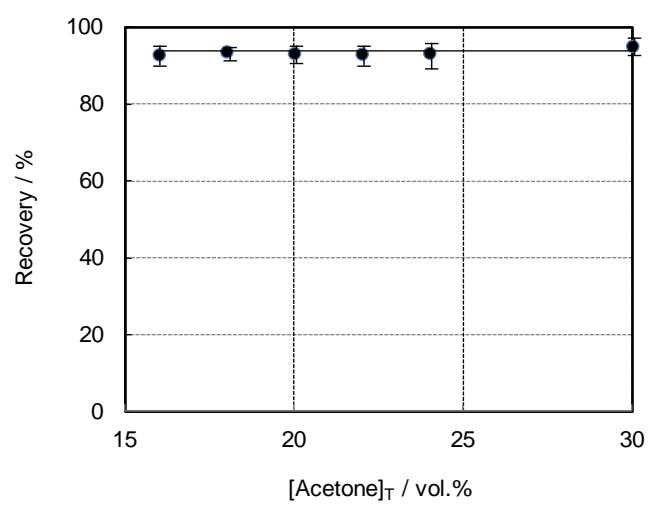

Figure 2. Influence of the acetone concentration on the HoLLE of palladium from $\mathrm{HNO}_{3}$ solution. Added palladium weight: $1 \mathrm{mg}$, [Ammonia $]_{\mathrm{T}}=0.267 \mathrm{M}, \mathrm{pH} 2.00$, $[\text { Zonyl FSA }]_{\mathrm{T}}=1.00 \mathrm{vol} . \%$.

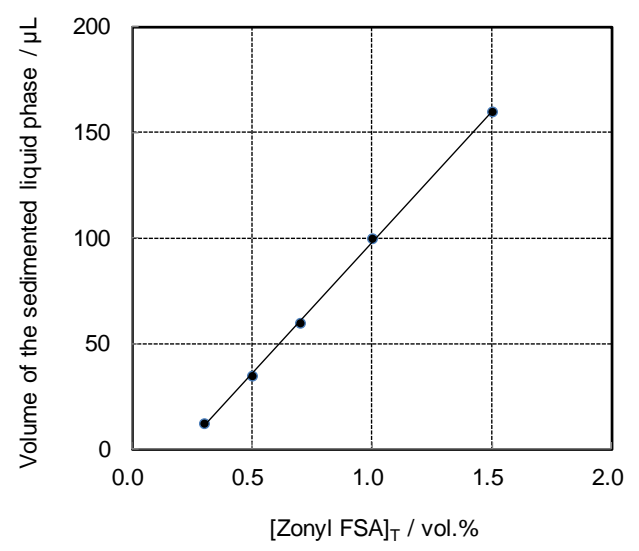

(a)

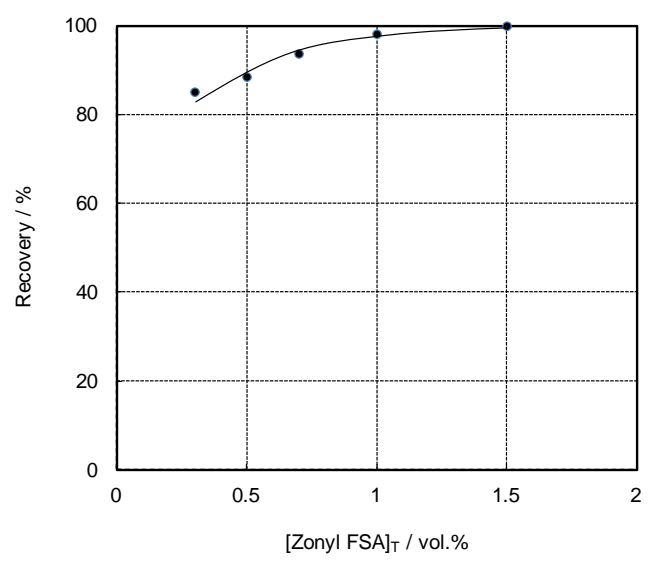

(b)

Figure 3. Influence of the Zonyl FSA concentration on the HoLLE of palladium from $\mathrm{HNO}_{3}$ solution. Added palladium weight: $1 \mathrm{mg},[\text { Ammonia }]_{\mathrm{T}}=0.267 \mathrm{M}, \mathrm{pH} 2.00$, [Acetone $_{\mathrm{T}}=22 \mathrm{vol} . \%$.

increasing Zonyl FSA concentration, and was almost 100\% above 1.0 vol.\% Zonyl FSA. Therefore, the Zonyl FSA concentration was set at $1.0 \mathrm{vol} . \%$ for the remainder of the experiment.

\subsection{HoLLE of Palladium Plating Water}

Palladium recovery from plating water containing a palladium-ammine complex was performed under the HoLLE conditions optimized for pure palladium solutions. Similar to the pure palladium solution, HoLLE was performed with and without ammonia addition for the plating water. The phase separation occurred in the absence of ammonia because the palladium-ammine complex already existed in the plating water. Therefore, the extraction was performed without ammonia addition. The phase separation of plating water with $1 \mathrm{mg}$ palladium was achieved by HoLLE using Zonyl FSA (Figure 4). Approximately $90 \mu \mathrm{L}$ of each aqueous phase and sedimented liquid phase were collected using a microsyringe. These solutions were then dropped onto a filter paper and analyzed by X-ray fluorescence. The results of the analyses are shown in Figure 5. A peak for palladium was not detected in the X-ray fluorescence spectrum of the aqueous phase, but was observed in the spectrum of the sedimented liquid phase. The ICP-OES analysis of the aqueous phase showed that $96.6 \%$ of the palladium was extracted into the sedimented liquid phase. The volume ratio was calculated as follows:

$$
\text { Volume ratio }=(\mathrm{mL} \text { of the aqueous phase }) /(\mathrm{mL} \text { of the sedimented liquid phase })=50 / 0.09=556
$$

These results suggest that the HoLLE-based approach effectively concentrated palladium from plating water. 


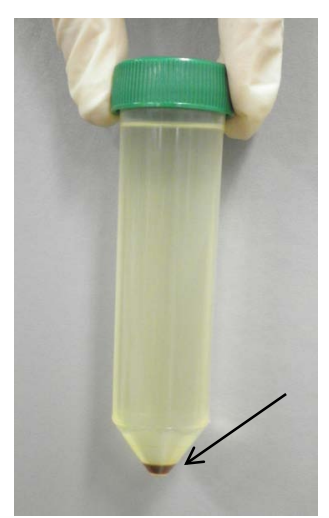

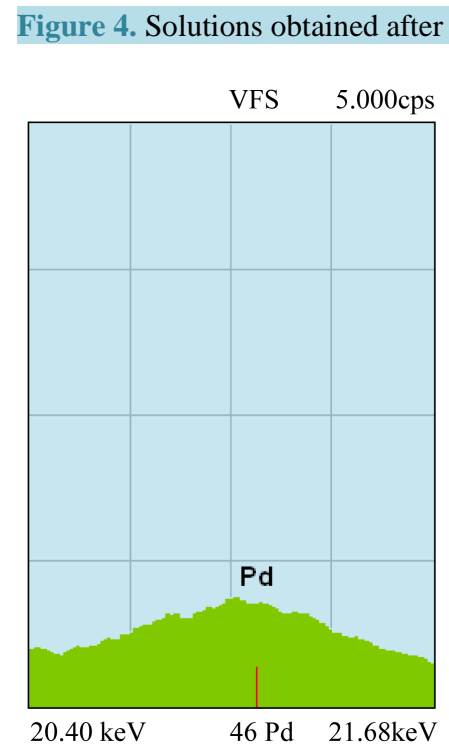

(a)

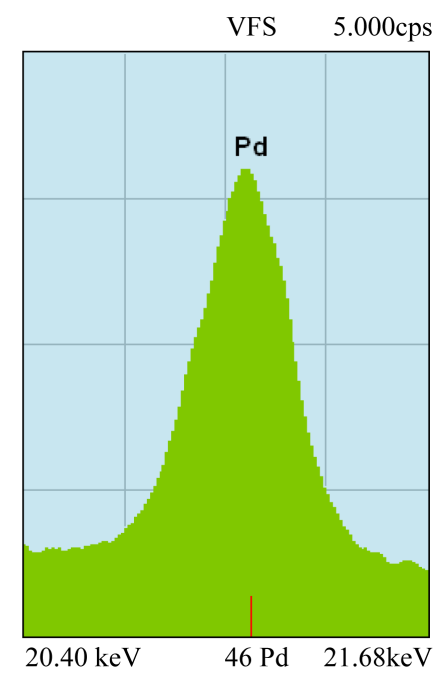

(b)

Figure 5. XRF evaluation after the HoLLE of palladium from plating water. (a) Aqueous phase, (b) Sedimented liquid phase, Added palladium weight: $1 \mathrm{mg}, \mathrm{pH} 2.00$, [Acetone $]_{\mathrm{T}}=22$ vol. $\%$, $[\text { Zonyl FSA }]_{\mathrm{T}}=$ 1.00 vol.\%, (XRF measurement conditions: X-ray diameter: $1.2 \mathrm{~mm}$, time: $300 \mathrm{~s}$, voltage: $50 \mathrm{kV}$ ).

To assess the applicability of this approach to industrial plating water, palladium was also concentrated from plating water by HoLLE. The total volume was increased to $1000 \mathrm{~mL}$, which is twenty times higher than the original volume, whereas the remaining conditions were maintained identical to the optimized ones. Phase separation was satisfactorily completed (Figure 6). The ICP-OES analysis of the aqueous phase revealed that $99.9 \%$ of the palladium was extracted into the sedimented liquid phase. The volume ratio was calculated as follows:

$$
\text { Volume ratio }=(\mathrm{mL} \text { of the aqueous phase }) /(\mathrm{mL} \text { of the sedimented liquid phase })=1000 / 2.5=400
$$

This data showed that HoLLE resulted in high volume ratio and high recovery upon scale-up. Moreover, because of scale-up experiment without centrifugal separation, it was confirmed that phase separation was satisfactorily completed with only addition of reagents.

The palladium concentration of these plating water samples was $33.3 \mathrm{mg} \cdot \mathrm{L}^{-1}$, which was equivalent to 1 and $20 \mathrm{mg}$ palladium in 30 and $600 \mathrm{~mL}$ solutions, respectively. Industrial plating wastewater results from a mixture of plating bath and rinse water bath and has been reported to contain 100 - $400 \mathrm{mg} \cdot \mathrm{L}^{-1}$ of metals in Japan [30]. Therefore, the performance of HoLLE was evaluated in this concentration range. Under optimized HoLLE conditions, phase separation was satisfactorily completed for plating water containing $33.3-289 \mathrm{mg} \cdot \mathrm{L}^{-1}$. $88.0 \%$ of the palladium was extracted into the sedimented liquid phase from $289 \mathrm{mg} \cdot \mathrm{L}^{-1}$ palladium plating water. This 


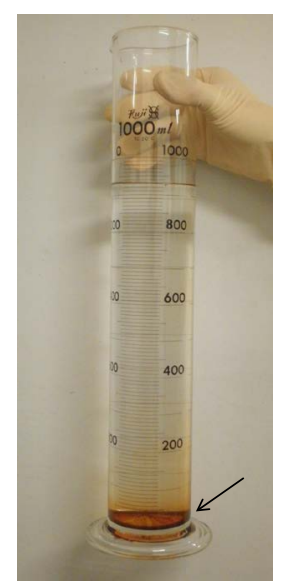

Figure 6. Solutions obtained after HoLLE of palladium plating water $(1000 \mathrm{~mL})$.

confirms that HoLLE effectively extracted palladium from wastewater in plating facilities. In this concentration range, the recovery gradually decreased with increasing palladium concentration (Figure 7). A recovery of 96.6\% was obtained from the $33.3 \mathrm{mg} \cdot \mathrm{L}^{-1}$ palladium plating water, suggesting that HoLLE should be performed from slightly diluted solutions to reduce interferences from coexisting substances such as buffer solutions.

The sedimented liquid phase contained palladium and Zonyl FSA. Back-extraction by addition of a solvent [31], recovery mediated by a chemically modified polymer gel [32], and scavenging by solid phase extraction [33] have been exploited to recover fluoro compounds. Therefore, it was thought that the metal could be isolated from the sedimented liquid phase by these methods.

\subsection{HoLLE of Real Palladium Plating Wastewater}

To confirm the effect of coexisting metals, except palladium, HoLLE was performed to real palladium-nickel plating wastewater generated in the plating industry. Plating water and plating wastewater in palladium-nickel plating compositions in palladium-nickel plating are shown in Table 2. Their base material was copper, and the plating metals consisted of nickel, gold, and palladium-nickel. During plating processes, the material passed through a plating bath and rinse water bath. It was confirmed that each metal concentration of plating wastewater was approximately 500 times lower than plating water (Table 2). The plating wastewater originated from diluted plating water because the base material and plating metal under palladium-nickel phase did not leach. The phase separation was satisfactorily completed in HoLLE for this plating wastewater. Further, the ICP-OES analysis of the aqueous phase revealed that $94.5 \%$ of the palladium was extracted into the sedimented liquid phase (Table 3). In addition, the recovery of the coexisting nickel and copper was $24.6 \%$ and $57.2 \%$, respectively. In other words, the weight percentage of the three component metals in plating wastewater changed as Pd $(62.1 \% \rightarrow 86.0 \%)$, $\mathrm{Ni}(37.1 \% \rightarrow 13.3 \%)$, and $\mathrm{Cu}(0.8 \% \rightarrow 0.7 \%)$. Hence, it was confirmed that the palladium was conveniently separated from coexisting metals. It was considered that this separation was achieved because of the formation of a palladium-ammine complex and the ionization state of coexisting metals such as nickel and copper. The volume ratio was calculated as follows:

$$
\text { Volume ratio }=(\mathrm{mL} \text { of the aqueous phase }) /(\mathrm{mL} \text { of the sedimented liquid phase })=50 / 0.1=500
$$

These results show that it is possible to simultaneously concentrate palladium and separate coexisting substances.

\section{Conclusion}

Palladium was extracted from plating water by HoLLE in the presence of Zonyl FSA. For plating water with 1 mg palladium, palladium recovery amounted to $96.6 \%$, and the volume ratio was 556 (50 mL $\rightarrow 0.09 \mathrm{~mL}$ ). Performance assessment for the potential use of this approach for wastewater treatment demonstrated that the phase separation was satisfactorily achieved at the scaled-up volumes. Moreover, this extraction approach was applicable 


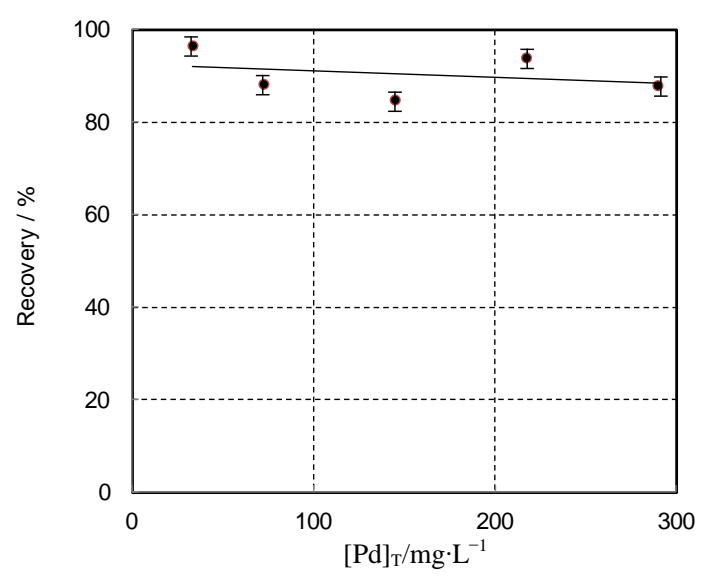

Figure 7. Influence of the palladium concentration on the HoLLE from plating water. $\mathrm{pH} 2.00$, [Acetone $]_{\mathrm{T}}=22$ vol. $\%$, $[\text { Zonyl FSA }]_{\mathrm{T}}=1.00 \mathrm{vol} . \%$.

Table 2. Concentration of plating water and plating wastewater in plating industry.

\begin{tabular}{ccc}
\hline & Plating water $\left(\mathrm{mg} \cdot \mathrm{L}^{-1}\right)$ & Plating waste water $\left(\mathrm{mg} \cdot \mathrm{L}^{-1}\right)$ \\
$\mathrm{Pd}$ & 15200 & 29.6 \\
$\mathrm{Ni}$ & 9280 & 17.7 \\
$\mathrm{Au}$ & Not detected & Not detected \\
$\mathrm{Cu}$ & 180 & 0.4 \\
\hline
\end{tabular}

Table 3. Influence of coexisting substances on the HoLLE from plating wastewater.

\begin{tabular}{cccc}
\hline & $\begin{array}{c}\text { Weight in the plating } \\
\text { waste water (mg) }\end{array}$ & $\begin{array}{c}\text { Weight in the sedimented } \\
\text { liquid phase (mg) }\end{array}$ & Recovery (\%) \\
\hline $\mathrm{Pd}$ & 0.888 & 0.839 & 94.5 \\
$\mathrm{Ni}$ & 0.531 & 0.130 & 24.6 \\
$\mathrm{Au}$ & Not added & - & - \\
$\mathrm{Cu}$ & 0.012 & 0.007 & 57.2 \\
\hline
\end{tabular}

to plating wastewater at standard industrial concentrations, as well as the real plating wastewater. This knowledge is expected to lead to the development of new separation and concentration technologies of rare metals from real plating wastewater.

\section{Acknowledgements}

These results are related to special power supply location prefecture technology promotion work by the Ministry of Education, Culture, Sports, Science and Technology, Japan. The authors would like to express their appreciation to Ibaraki Plating Kogyo Co., Ltd. (Ibaraki, Japan) for providing palladium plating water and real palladium plating wastewater. Finally, the authors would like to thank Enago (www.enago.jp) for the English language review.

\section{References}

[1] Kato, M., Senda, K., Musha, Y., Sasano, J., Okinaka, Y. and Osaka, T. (2007) Electrodeposition of Amorphous Gold Alloy Films. Electrochimica Acta, 53, 11-15. http://dx.doi.org/10.1016/j.electacta.2007.01.045

[2] Rouya, E., Stafford, G.R., Bertocci, U., Mallett, J.J., Schad, R., Begley, M.R., Kelly, R.G., Reed, M.L. and Zangari, G. 
(2010) Electrodeposition of Metastable Au-Ni alloys. Journal of the Electrochemical Society, 157, D396-D405. http://dx.doi.org/10.1149/1.3421749

[3] Beattie, R.W. (1962) Palladium Plating on Telephone Plugs and Sockets. Platinum Metals Review, 6, 52-56.

[4] Philpott, J.E. (1960) Palladium Plating of Printed Circuits. Platinum Metals Review, 4, 12-14.

[5] Kim, Y.M., Park, J. and Kim, Y. (2012) Effect of Pd Thickness on the Interfacial Reaction and Shear Strength in Solder Joints between Sn-3.0Ag-0.5Cu Solder and Electroless Nickel/Electroless Palladium/Immersion Gold (ENEPIG) Surface Finish. Journal of Electronic Materials, 41, 763-773. http://dx.doi.org/10.1007/s11664-012-1921-0

[6] Zuo, Y., Tang, J., Fan, C., Tang, Y. and Xiong, J. (2008) An Electroless Plating Film of Palladium on 304 Stainless Steel and Its Excellent Corrosion Resistance. Thin Solid Films, 516, 7565-7570. http://dx.doi.org/10.1016/j.tsf.2008.04.049

[7] Galvan-Arellano, M., Diaz-Reyes, J. and Pena-Sierra, R. (2010) Ohmic Contacts with Palladium Diffusion Barrier on III-V Semiconductors. Vacuum, 84, 1195-1198. http://dx.doi.org/10.1016/j.vacuum.2009.10.024

[8] Ministry of Economy, Trade and Industry (Japan) (2005) A Study of the Model Circulation System in Recycling of Plating Sludge. (In Japanese)

[9] Aktas, S. (2011) Rhodium Recovery from Rhodium-Containing Waste Rinsing Water via Cementation Using Zinc Powder. Hydrometallurgy, 106, 71-75. http://dx.doi.org/10.1016/j.hydromet.2010.12.005

[10] Lee, H.Y. (2013) Separation and Recovery of Nickel from Spent Electroless Nickel-Plating Solutions with Hydrometallurgical Processes. Separation Science and Technology, 48, 1602-1608. http://dx.doi.org/10.1080/01496395.2012.756523

[11] Hermandez-Tapia, J.R., Vazquez-Arenas, J. and Gonzalez, I. (2013) A Kinetic Model to Describe the Nickel ElectroRecovery from Industrial Plating Effluents under Variable Electrolyte Conductivity. Electrochimica Acta, 103, 266274. http://dx.doi.org/10.1016/j.electacta.2013.04.122

[12] Hankin, A. and Kelsall, G.H. (2012) Electrochemical Recovery of Nickel from Nickel Sulfamate Plating Effluents. Journal of Applied Electrochemistry, 42, 629-643. http://dx.doi.org/10.1007/s10800-012-0447-8

[13] Dutra, A.J.B., Rocha, G.P. and Pombo, F.R. (2008) Copper Recovery and Cyanide Oxidation by Electrowinning from a Spent Copper-Cyanide Electroplating Electrolyte. Journal of Hazardous Materials, 152, 648-655. http://dx.doi.org/10.1016/j.jhazmat.2007.07.030

[14] Jin, G., Wang, X., Fu, Y. and Do, Y. (2012) Preparation of Tetraoxalyl Ethylenediamine Metamine Resin GraftedCarbon Fibers for Nano-Nickel Recovery from Spent Electroless Nickel Plating Baths. Chemical Engineering Journal, 203, 440-446. http://dx.doi.org/10.1016/j.cej.2012.07.055

[15] Rahman, I.M.M., Furusho, Y., Begum, Z.A., Izatt, N., Brucning, R., Sabarudin, A. and Hasegawa, H. (2011) Separation of Lead from High Matrix Electroless Nickel Plating Waste Solution Using an Ion-Selective Immobilized Macrocycle System. Microchemical Journal, 98, 103-108. http://dx.doi.org/10.1016/j.microc.2010.12.005

[16] Ookubo, T., Nishihama, S. and Yoshizuka, K. (2013) Separation and Recovery of Nickel from Waste Electroless Nickel-Phosphorous Plating Solution. Solvent Extraction Research and Development, Japan, 20, 149-157. http://dx.doi.org/10.15261/serdj.20.149

[17] Li, L.Q. and Zhong, H. (2012) Separation and Recovery of Copper(II), Nickel(II) from Simulated Plating Wastewater by Solvent Extraction Using Lix984. Advanced Materials Research, 365, 252-259. http://dx.doi.org/10.4028/www.scientific.net/AMR.365.252

[18] Okada, M., Kimura, S., Murayama, N., Shibata, J. and Otani, K. (2010) Application of Solvent Extraction Using Synergistic Effect to Electroless Nickel Plating Waste Liquor. Resources Processing, 57, 109-113. http://dx.doi.org/10.4144/rpsj.57.109

[19] Warner, N. and Free, M.L. (2009) The Electrochemical Recovery of Metallic Palladium from Spent Electroless Plating Solution. JOM, 61, 27-30. http://dx.doi.org/10.1007/s11837-009-0148-x

[20] Farrar, L.S. (1987) Recovery of Palladium from Plating Operations. Plating and Surface Finishing, 3, 60-61.

[21] Ochromowicz, K. and Chmielewski, T. (2011) Solvent Extraction in Hydrometallurgical Processing of Polish Copper Concentrates. Physicochemical Problems of Mineral Processing, 46, 207-218.

[22] Flett, D.S. (2005) Solvent Extraction in Hydrometallurgy: The Role of Organophosphorus Extractants. Journal of Organometallic Chemistry, 690, 2426-2438. http://dx.doi.org/10.1016/j.jorganchem.2004.11.037

[23] Silva, J.E., Paiva, A.P., Soares, D., Labrincha, A. and Castro, F. (2005) Solvent Extraction Applied to the Recovery of Heavy Metals from Galvanic Sludge. Journal of Hazardous Materials, B120, 113-118. http://dx.doi.org/10.1016/j.jhazmat.2004.12.008

[24] Igarashi, S. and Yotsuyanagi, T. (1992) Homogeneous Liquid-Liquid Extraction by pH Dependent Phase Separation with a Fluorocarbon Ionic Surfactant and Its Application to the Preconcentration of Porphyrin Compounds. Mikrochi- 
mica Acta, 106, 37-44. http://dx.doi.org/10.1007/BF01242697

[25] Takagai, Y. and Igarashi, S. (2002) Homogeneous Liquid-Liquid Extraction and Micellar Electrokinetic Chromatography Using Sweeping Effect Concentration System for Determination of Trace Amounts of Several Polycyclic Aromatic Hydrocarbons. Analytical and Bioanalytical Chemistry, 373, 87-92. http://dx.doi.org/10.1007/s00216-002-1243-9

[26] Fuchimukai, J., Yamaguchi, H., Meguro, Y., Kubota, T. and Igarashi, S. (2006) Highly Efficient Homogeneous LiquidLiquid Extraction of Lanthanoid Ions in a Strong Acidic Solution. Solvent Extraction Research and Development, Japan, 13, 139-146.

[27] Yamaguchi, H., Itoh, S., Igarashi, S. and Kobayashi, T. (2005) Homogeneous Liquid-Liquid Extraction of Metal1,10-Phenanthroline Chelates in a Weak Acidic Solution. Bunseki Kagaku, 54, 227-230. (In Japanese) http://dx.doi.org/10.2116/bunsekikagaku.54.227

[28] Kato, T., Igarashi, S., Ishiwatari, Y., Furukawa, M. and Yamaguchi, H. (2013) Separation and Concentration of Indium from a Liquid Crystal Display via Homogeneous Liquid-Liquid Extraction. Hydrometallurgy, 137, 148-155. http://dx.doi.org/10.1016/j.hydromet.2013.06.004

[29] Sudo, T. and Igarashi, S. (1996) Homogeneous Liquid-Liquid Extraction Method for Spectrofluorimetric Determination of Chlorophyll A. Talanta, 43, 233-237. http://dx.doi.org/10.1016/0039-9140(95)01748-8

[30] Inamoto, J. (2011) The Basic Wastewater Treatment and the Response to the New Wastewater Regulation. Journal of the Surface Finishing Society of Japan, 62, 535-540. (In Japanese) http://dx.doi.org/10.4139/sfj.62.535

[31] Takagai, Y. and Igarashi, S. (2003) Selective Extraction and Isolation of Vitamin $B_{12}$ Using Homogeneous Liquid-Liquid Extraction with Perfluoro Surfactant. Bulletin of Chemical Society of Japan, 76, 1595-1600. http://dx.doi.org/10.1246/bcsj.76.1595

[32] Butsugan, M. and Igarashi, S. (2009) Collection and Recovery Agent for Surfactant. Japanese Patent No. 207994. (In Japanese)

[33] Japanese Standard Association (2011) Testing Methods for Perfluorooctane Sulfonate (PFOS) and Perfluorooctanoate (PFOA) in Industrial Water and Wastewater (JIS K 0450-70-10). (In Japanese) 